\title{
The ability of the emergency medical service personnel to take patients' medical history
}

\author{
Ali Sadrollahi' ${ }^{1}$, Adeleh Gharataghani ${ }^{2}$, Mehdi Mahmoudi ${ }^{3}$, Fardaneh Gholipour ${ }^{4}$ \\ 'Department of Nursing Science, Bandar Gaz Branch, Islamic Azad University, Bandar Gaz, Iran \\ 2Department of Clinical Affairs, Golestan University of Medical Sciences, Gorgan, Iran \\ ${ }^{3}$ Department of Nursing Science, Bandar Gaz Branch, Islamic Azad University, Bandar Gaz, Iran \\ ${ }^{4}$ Department of Nursing, Khalkhal Branch, Islamic Azad University, Khalkhal, Iran
}

Received: 22 July 2017

Accepted: 18 September 2017

Published online: 26 September 2017

*Corresponding author: Al Sadrollahi; Department of Nursing Science, Bandar Gaz Branch, Islamic Azad University, Bandar Gaz, Iran Tel: +98-9382626127

Email: ali.sadrollahi@yahoo.com

Competing interests: None.

Funding information: This study was a part of a research proposal (No. 98121) and funded by the Deputy of Research, Islamic Azad University.

Citation: Sadrollahi A, Gharataghani A, Mahmoudi M, Gholipour F. The ability of the emergency medical service Personnel to take patients' medical history. Journal of Emergency Practice and Trauma 2018; 4(2): 55-61. doi: 10.15171/jept.2017.32.

\begin{abstract}
Objective: The key point to detect patients' need in pre-hospital emergency is to have high ability to take medical history. All research findings show that this ability is low. The objective of this research is to investigate the ability to take medical history of patients among the personnel of pre-hospital emergency medical service (EMS) in Golestan province, Iran.

Methods: This research was a descriptive cross-sectional study carried in 2016. The population included non-staff technicians and an operator working in the message center $(\mathrm{N}=171)$. The samples were selected using multi-stage cluster sampling. Data were collected by a researcher-developed questionnaire. The collected data were analyzed by SPSS software version 16 conducting descriptive and inferential statistics. All tests were administered at a significance level of $P<0.05$.

Results: One hundred sixty-five $(96.5 \%)$ participants were male. The mean score of the ability to take medical history was $58.4 \pm 11.1$. Therefore, 95 participants $(58.3 \%)$ had poor ability and 64 participants (39.3\%) owned moderate ability. The highest score concerning the ability to take medical history was for the aspect of professional knowledge (mean rank $=5)$. The most influential aspect in the ability was respectively for 'professional knowledge' $(P=0.0001$, Beta $=0.509)$. Pearson correlation coefficient indicated a relationship $(r=-0.149, P=0.05)$ between the ability to take medical history and age. Conclusion: The results of the current study indicated that the ability to take medical history among the personnel of pre-hospital medical emergency of Golestan province was low. Therefore, a thorough review of trainings promoting personnel's professional knowledge is urgently required.

Keywords: Medical history, Emergency, Patient, Pre-hospital
\end{abstract}

\section{Introduction}

Emergency medical service (EMS) was formed to provide pre-hospital medical service for patients (1). In order to protect people's lives due to the fact that during the service even a second or a minute is critically important (2). Those working in EMS as medical care providers have received necessary trainings of emergency medicine to examine and look after the patients (3). How to take medical history is among the most important necessary trainings that care providers have received to be able to collect and keep crucial and complete information on patients (4). Taking medical history has been emphasized hugely in medical literature (5). Medical history is an account of a patient's current and previous medical problems describing his/ her physical and mental conditions. It acts as the axis of medical care provided for the patient and the key to know the patient's special needs (6). Patient's medical history helps to diagnose his/her problems and find his/ her social, mental, and physical backgrounds affecting his/her health (7). Medical history is so significant that it can help doctors make accurate diagnoses in over $80 \%$ of the cases, without any clinical examination or laboratory tests. The content of medical history suggests the volume of collected information and clinical examinations carried out so far (6). Medical history plays a pivotal role in reducing medical errors, following the medical procedures, speeding up patient's recovery, and decreasing hospital expenses $(5,6)$.

Creating a medical history, many doctors face troubles during their medical examinations and relationship with patients (7). Therefore, the created medical history has serious problems (4). The inability to take a complete 
medical history is due to medical-providers' lack of skill in taking medical history and their negligence in patients' conditions (8). The results of the research done by Arora et al in 2014 showed that in patients admitted to the emergency department poor communication between medical care providers and patients was among the preventable errors during medical examinations which seriously affected the quality of medical history (7). Research findings of Birks et al in 2013 indicated that the personnel of the emergency department for outpatients were inept at medical history (9). Also, research findings by Abelsson and Lindwall in 2012 confirmed the high ability of nurses in pre-hospital emergency services department in initial examination of trauma patients (10). Lammers et al in 2012 maintained that their inability in taking a complete medical history of children was the main reason of their incapability in medical and clinical management of communicating with young patients in pre-hospital services (11).

Communicative limitations, limited access to the medical background of the patient, and shortage of time in taking medical history are among the problems leading to lowquality of medical history in medical emergency (7). On the other hand, personnel working in the medical emergency department have different academic degrees and training courses, bringing about a change in the quality of taking medical history. In order to improve these services, the EMS system should be evaluated. Therefore, it is really crucial to know the strengths and weaknesses in the process of taking medical history done by the prehospital emergency personnel. This can let personnel exchange their experiences, improve the medical quality, and better protect patients' lives.

As a result, this research tried to investigate the EMS personnel's ability to take medical history of patients in Golestan province, Iran, due to the fact that most of the relevant studies are done in other medical groups.

\section{Methods}

This descriptive cross-sectional research was conducted in 2016. The research used Quota and multistage sampling designs. The case study included the non-staff technicians and operators of the Golestan 115 EMS. The population included staff technicians and EMS 115 operators in Golestan province, Iran. Applying Cochran formula $\left(\mathrm{N}=\mathrm{Z}^{2} \times \mathrm{P}(1-\mathrm{P}) / \mathrm{d}^{2}\right)$, the sample size was 171 people $(\mathrm{Z}=1.96, P=0.68, \mathrm{~d}=0.05)$. The sample size had a level of significance of $95 \%$. The inclusion criteria were age (over 22 years of age), residence in the province, experience ( 1 year formal clinical activities), and conscious oral consent. Participants had the freedom to refuse to answer the questionnaire during the work or interview.

Coordinating with the supervisors of EMS 115 bases in the province, firstly the total number of medical emergency districts in the province was determined in order to collect the samples. These districts had to satisfy a criterion. Each district had to own an independent EMS 115 center. Then, the number of bases in each district was determined. Some bases were chosen randomly in proportion to the number of bases in each district. Accordingly, 4 districts, along with 14 bases, were chosen. In the next step, samples were chosen, by applying Quota sampling design, in proportion to the personnel population in chosen bases and also in regard with the inclusion criteria. The amount of quota in each base was different. The individuals chosen to be studied were replaced by other alternatives if they refused to participate. Those who agreed to participate received the questionnaire (as a method of data collection) in their bases and EMS 115 centers. Prior to the questionnaire distribution, they were informed about research objectives and were guided how to fill out the questionnaire. Questionnaires were filled out individually and privately by technicians. If any part of the questionnaire had an incomplete piece of information, the respondent would be asked to complete it. Then, the questionnaires were collected immediately after they were completed.

The first part of the questionnaire contained the demographic information, including variables like age, gender, academic degree (education), marital status, work experience, and type of employment (formal and contract employee means the employee must have a letter of appointment in which 'contract' or 'formal' is mentioned. This means the organization has a 5 -year or longer period contract with the employee). The second part included a researcher-developed questionnaire regarding the ability to take medical history from the patient during emergencies. After analyzing the existing literature, scientific texts, and previous researches (6), 25 questions were designed in the questionnaire evaluating the ability to take medical history during emergencies. The rating of each question, according to the Likert-scale, included Always (4), Often (3), Sometimes (2), Hardly (1), and Never (0). The maximum point in the questionnaire was 100 and the minimum was 0 . Therefore, if the sum of the point in a questionnaire was $0-60$, the respondent had a low ability to take medical history, if the sum point was $61-80$, he/she had an average ability to take medical history, and if the sum point of the questionnaire was 81100 , he/she had a high (optimal) ability to take medical history. The questionnaire evaluated 5 aspects of the required ability to take medical history. Topics and aspects were made according to the content of each question and their seeming similarity. The level of 'respect for patient' was the aspect which included 3 questions ( $0-12$ points), the level of 'knowledge about how to communicate with patients' had 3 questions (0-12 points), 'skill' was the aspect which had 3 questions (0-12 points), 'professional knowledge' had 12 questions ( 0 -48 points), and 'decisionmaking and performance' was the aspect which included 4 questions (0-16 points). A respondent possessed the ability in each aspect only if he/she achieved half or over 
half of the points in the related section. The more points the respondent achieved, the higher ability he/she had in the related aspect. A validity review of the content and a formal review of the tool were done quantitatively and qualitatively. In qualitative review of validity, the tool was given to 10 expert professors. They were asked to score each question according to the set objectives in the questionnaire from 4 for 'Entirely Appropriate', to 3 for 'Appropriate', to 2 for 'Fairly Appropriate', to 1 for 'Inappropriate', to 0 for 'Entirely Inappropriate'. Also, they were asked to add their comments on each question under the question. Afterwards, the average score given by expert professors was determined for each question. Eventually, the content and wording of some questions were revised according to their comments. As a result, the qualitative validity of the questionnaire was confirmed. In quantitative review of validity of the content, the findings showed that 19 items possessed CVI scores more than 0.97. The remained items had CVI scores between 0.700.79 . The result of $\mathrm{McNemar}$ test showed that all items had $P$ values of over 0.05 . The kappa coefficients of 20 items were 0.75 or more and the kappa coefficients of the rest of items were from 0.40 to 0.74 . In order to review the reliability, the questionnaires were given to 20 technicians of medical emergency for a pilot study. This was in two steps with a 72-hour interval between the first step and the second step. The total Cronbach's alpha of this review was $\alpha=0.78$.

Data were analyzed by SPSS software version 11.5. Descriptive statistics were used for average and standard deviation. The Kolmogorov-Smirnov test was used to check the normality of the data. Although the results of Kolmogorov-Smirnov test- $a>0.05$ - was not meaningful for variables including age, the score for ability to take medical history, the score for the level of respect for patients' beliefs, professional knowledge, and knowledge of how to communicate with patients and skill, the assumed normality of the research population did exist in this study. This research used parametric tests for the analyses. The relationship between the quantitative variables like age, work experience, and the ability to take medical history was studied by the Pearson correlation coefficient test. The relationship between the related qualitative factors like gender, marital status, and education with the performance of taking medical history of patients was determined by $t$ test and analysis of variance (ANOVA). The effect of each area on the ability to take medical history was analyzed by multiple regression. The level of importance and ranking the domains of the ability to take medical history was evaluated by Friedman test. All analyses were carried out with level of significance equals $P<0.05$.

\section{Results}

One hundred sixty-five participants (96.5\%) were male. The average age of them was $31.8 \pm 6.01$. Most of the participants $(\mathrm{n}=121,70.8 \%)$ were married. Regarding the education, the majority of the participants (40.9\%) had B.Sc. degrees. Being studied for their employment contract, most of them (68.4\%) were officially employed. The average work experience of participants with 2-25 year work experience was $7.5 \pm 5.4$ (Table 1 ).

The average score of the ability to take medical history was $58.04 \pm 11.1$ up to a maximum of 93.1 and a minimum of 29.04. Among the participants, 95 (58.3\%) possessed poor ability, $64(39.3 \%)$ had moderate ability, and 4 (2.4\%)

Table 1. Relative and absolute frequency table along with the average of the ability to take medical history of patients in medical emergency in Golestan Province EMS according to demographic features in 2015

\begin{tabular}{|c|c|c|c|c|c|}
\hline Variations & Range & Distribution & Percent & Mean \pm SD & $P$ value \\
\hline \multirow{3}{*}{ Age } & $20-30$ & 79 & 46.5 & $59.6 \pm 11.1$ & \multirow{3}{*}{$P=0.05, r=-0.149$} \\
\hline & $31-40$ & 80 & 47.1 & $55.8 \pm 11.3$ & \\
\hline & $41-50$ & 11 & 6.4 & $62.3 \pm 7.7$ & \\
\hline \multirow{2}{*}{ Gender } & Female & 6 & 3.5 & $52.1 \pm 24.7$ & \multirow{2}{*}{0.3} \\
\hline & Male & 165 & 96.5 & $58.2 \pm 10.9$ & \\
\hline \multirow{2}{*}{ Marital Status } & Single & 149 & 29.2 & $58.3 \pm 12.2$ & \multirow{2}{*}{0.9} \\
\hline & Married & 121 & 70.8 & $58.07 \pm 10.6$ & \\
\hline \multirow{4}{*}{ Education } & Diploma & 33 & 19.3 & $56.09 \pm 10.3$ & \multirow{4}{*}{0.14} \\
\hline & A.S. & 65 & 38 & $58.01 \pm 13.3$ & \\
\hline & B.Sc. & 70 & 40.9 & $58.3 \pm 10.7$ & \\
\hline & M.Sc. & 3 & 1.8 & $64.04 \pm 1$ & \\
\hline \multirow{3}{*}{ Employment } & Training & 2 & 1.2 & $55.6 \pm 19.06$ & \multirow{3}{*}{0.6} \\
\hline & Contract & 52 & 30.4 & $57.04 \pm 10.4$ & \\
\hline & Official & 117 & 68.4 & $58.3 \pm 11.4$ & \\
\hline \multirow{5}{*}{ Work Experience } & $1-5$ & 74 & 43.3 & $60.02 \pm 12.6$ & \multirow{5}{*}{$P=0.8, \mathrm{r}=0.014$} \\
\hline & $6-10$ & 56 & 32.7 & $55.7 \pm 8.8$ & \\
\hline & $11-15$ & 27 & 15.8 & $55.3 \pm 10.3$ & \\
\hline & $16-20$ & 10 & 5.8 & $59.2 \pm 11.8$ & \\
\hline & $21-25$ & 4 & 2.3 & $68.5 \pm 4.1$ & \\
\hline
\end{tabular}


owned high ability to take medical history. The highest score of ability to take medical history was for the age group 41-50 (62.3 \pm 7.7$)$. The average score of the ability for female participants $(52.1 \pm 24.7)$ was less than that of male participants $(56.09 \pm 10.3)$. The lowest score of the ability to take medical history was for participants holding A.S. degrees $(56.09 \pm 10.3)$ and the highest score was for participants holding M.Sc. degrees (64.04 \pm 1$)$. The lowest score of the ability to take medical history, based on the type of employment, was for training program technicians (55.6 \pm 19.06$)$, and the highest score of the ability was for officially employed technicians $(58.3 \pm 11.4)$. The highest score of the ability to take medical history was for the participants who had from 21 to 25 -year work experience (Table 1).

Table 2 illustrates the average score of participants in different aspects of the ability to take medical history, showing that the aspect with the highest point was professional knowledge (mean rank=5) and the lowest point was for respect to patients' beliefs (mean rank $=1.7$ ), based on the Friedman Test of ranking the aspects.

The Pearson correlation coefficient test displayed a meaningful relationship between the age variable of participants with the average ability to take medical history $(P=0.05 r=-0.149)$, while this meaningful relationship was not found in participants' work experience $(P>0.8$ $r=0.014$ ) (Table 1).

The result of $t$ test showed a non-significant difference between the ability to take medical history regarding gender variable $(P=0.3)$ and marital status $(P=0.9)$ (Table 1).

According to the results of ANOVA test, there was not a meaningful difference between the ability to take medical history, participants' level of education $(P=0.14)$, and their employment type $(P=0.6)$. Although their ability to take medical history was enhanced as their education improved a little (Table 1).

Prediction of the effect of each aspect of taking medical history on the ability to take medical history by multiple linear regression indicated that all the studied aspects of taking medical history were influential concerning the ability to take medical history. The most influential aspects for the ability to take medical history were respectively: professional knowledge $(P=0.0001, \beta=0.509)$, respect to patients' beliefs $(P=0.0001, \beta=0.239)$, communicating with patient $(P=0.0001, \beta=0.246)$, decision-making and performance $(P=0.008, \beta=0.145)$, and skill $(P=0.08$, $\beta=0.1$ ) (Table 3).

\section{Discussion}

The research findings showed that technicians and operators working in the EMS of Golestan province had low ability to take medical history. Only $2.4 \%$ of participants in this research possessed high ability to take medical history. Searches for studies on their ability to take medical history did not find any results. Some studies had examined the ability to take medical history in other fields and groups. Those research findings were not related to EMS since their clinical environment differed markedly. However, since people working in EMS are graduates of paramedicine, nursing, and medicine, previous research findings can be compared with the results of the current research. In a research done in the United States by Will et al in 2014, findings showed that participants possessed low ability in emergency skills which needed professional knowledge (12). The research carried out by Oostendorp et al in 2015, indicated that history taking was excellent (98.3\%) for the somatic dimension, very inadequate for cognition (43.1\%) and behavior (38.3\%), weak for emotion (27.8\%), and low for the social dimension (18.2\%) (13). The research findings of Abelsson et al in 2012 displayed that nurses working in the pre-hospital emergency services in Sweden maintained good quality in examining trauma patients (10). A clinical technician must know what information should be collected, how to interpret the information, and finally how to evaluate them (6). It seems that one of the influential reasons of the weak ability to take medical history is that the EMS 115 technicians are not aware of legal and judicial issues. They also feel that it is not necessary to take a complete medical history of patients (14). On the other hand, another reason is technicians' inappropriate and different levels of education. This reduces the quality of medical history and clinical measure drastically (15). In fact, the reasons mentioned above are rooted in the problem which exists in Iran. In Iran, only a single occupational category has been defined for paramedic medical emergency technicians. This definition does not include level of education as well as the field of study. Organizational problems (like lack of human resources and training insufficiency) and lack

Table 2. The average distribution of the ability to take medical history of patients in medical emergency in Golestan province EMS based on importance in 2015

\begin{tabular}{lllll}
\hline Aspect of ability to take medical ability & Mean \pm SD & Mean rank & Lower bound of point & Upper bound of point \\
\hline Respect to Patient's Beliefs & $4.6 \pm 2.1$ & 1.7 & 0 & 12 \\
\hline Professional Knowledge & $27.5 \pm 6.2$ & 5 & 0 & 48 \\
How to Communicate with patient & $6.6 \pm 2.2$ & 2.7 & 0 & 12 \\
\hline Decision-making and Performance & $7.6 \pm 2.5$ & 3.2 & 0 & 16 \\
Skill & $5.6 \pm 2.3$ & 2.2 & 0 & 12 \\
\hline
\end{tabular}


Table 3. Results of anticipating each aspect of taking medical history on the ability to take medical history of patients in medical emergency in Golestan province EMS, in $2015^{\text {a }}$

\begin{tabular}{llllll}
\hline Aspect of Ability to take Medical History & $\boldsymbol{P}$ & $\boldsymbol{t}$ & Beta & SE & 0.239 \\
\hline Respect to Patients' Beliefs & 0.0001 & 4.958 & 0.509 & 0.005 \\
\hline Professional Knowledge & 0.0001 & 9.1 & 0.246 & 0.011 \\
How to Communicate with Patient & 0.0001 & 5.325 & 0.145 & 0.011 \\
Decision-making and Performance & 0.008 & 2.705 & 0.1 & 0.011 \\
Skill & 0.08 & 2.192 & 0.031 \\
\hline
\end{tabular}

${ }^{a}$ Adjusted $R$ Square $=0.685, R^{2}=0.694, R=0.833$.

of motivation are also among the main reasons of taking poor medical history.

In the current research, professional knowledge had the highest importance among other factors involving the ability to take medical history. Also, the results of multiple regression test showed that professional knowledge was the most influential factor in taking medical history $(\beta=0.509)$. In a research conducted by Pan et al in 2014 , lack of knowledge to examine the health condition of patients was emphasized as one of the main reasons of failure to examine patients' health conditions (16). Other studies show that delay in primary cares, insufficient care while transferring patients, and poor communication are among the frequent errors in preventable cases (17). The most important duty of emergency clinical care providers is to examine the patient properly and communicate with him/her to plan and determine proper medical measures $(5,6)$. Lack of professional knowledge can affect all areas of examining, perusing, curing, and carrying out various clinical interferences concerning the patient. Also, lack of professional knowledge can be rooted in the lack of facilities, resources, equipment, insufficient and inappropriate trainings, the gap between theory and practice or training and treatment, lack of expert and competent instructors, and lack of motivation among the personnel (17).

In this research, although the lowest point was related to respect for patient, the result of Multiple Regression showed that respect for patient was one of the influential aspects of the ability to take medical history in the EMS of Golestan province $(\beta=0239)$. The nature of treating the patient along with the medical ethics is of great importance. Low score in respect for patients signifies negligence to patients' requests during the examination and treatment. But attention to patients' request causes positive psychological reactions and higher satisfaction. This effect is created because when patients' personal features and requests are heard, the patients themselves and their companions cooperate more (18). As a result, personnel can communicate better and the quality of examining patients improves. Communicative limitations, shortage of time, patients' state of needing emergency medical care in pre-hospital emergency medical centers justify the low score of respect for patients' beliefs (19).
Although there was no meaningful difference, in this research, between gender and the ability to take medical history, female personnel got lower scores than males. However, it was not beyond expectations that male personnel obtain higher scores for the ability to take medical history since they are employed more in medical emergency clinical services. However, since female personnel work in EMS 115 message centers, and they have the first contacts with the public, they must have adequate ability and skill to take medical history from the callers in order to give proper advice and also to gather primary clinical information and diagnosis. Low score in taking medical history can increase the mistakes in admitting non-emergency patients and incurs huge expenses of transferring clinical services to non-emergency centers for EMS 115.

Another controversial finding of this research is that personnel with more age or work experience got higher scores. However, this relation for the age variable had a weak correlation coefficient, so there was not a meaningful relation regarding the work experience. In reality, higher age is related to higher work experience, so this brings more skill in dealing with the problems; it causes service providers to deal with patients with calmness and patience. On the other hand, more work experience helps the personnel make decisions based on reality. This enhances their ability to take medical history. Many research findings show that those who give clinical service utilize their previous experience in clinical decision-making. This is done via a proper combination and comparison of their previous experiences and current information at the scene and reaching an appropriate decision $(20,21)$. This happens now and then due to the special work in prehospital emergency and the need to use a huge amount of information in a short period of time. In fact, the number of samples is another reason which affects the final results.

\section{Conclusion}

Ample knowledge and experience of different occasions and events are among the leading factors in pre-hospital emergency decision-making. The results of this research illustrated that dynamic and altering conditions in emergency service, along with, uncertain and changing conditions of patients, require the personnel to be 
competent decision-makers so that they could combine their technical skills and professional knowledge and make accurate and appropriate clinical decisions about patients' health conditions. Thus, adequate and appropriate trainings on examining patients are of great significance.

\section{Limitations of study}

One of the limitations in this research was the lack of appropriate tools to study the ability to take medical history in pre-hospital emergency. It is suggested that appropriate tools are made for studying the ability in this section. Another limitation was the limited number of samples. It is recommended that further studies are carried out with a higher population and more samples. Also, the process of taking medical history from the patient is suggested to be analyzed by direct observation in a real environment.

\section{Acknowledgments}

Our most sincere thanks go to all personnel of EMS 115 in Golestan province, Iran who helped us with their patience.

\section{Ethical issues}

Some ethical considerations were also taken during administering the questionnaires, including coordination with the medical emergency officials during the sampling, informing the participants about using the information, total confidentiality regarding the collected data, and voluntary participation in the study. All participants gave verbal consent to participate in the study.

\section{Authors' contributions}

AS performed the data collection, literature review, and prepared the first draft of the manuscript, supervised the study made critical revisions to the paper and prepared the last revision of the manuscript. AG performed the data collection, literature review, and prepared the first draft of the manuscript. MM, and FG supervised the study, performed data analysis and helped in the process of sampling.

\section{References}

1. Dyson K, Bray JE, Smith K, Bernard S, Straney L, Finn J. Paramedic exposure to out-of-hospital cardiac arrest resuscitation is associated with patient survival. Circ Cardiovasc Qual Outcomes 2016; 9(2): 154-60. doi: 10.1161/circoutcomes.115.002317.

2. Shiraishi Y, Kohsaka S, Harada K, Miyamoto T, Tanimoto $\mathrm{S}$, Iida K, et al. Correlation of pre- and in-hospital systolic blood pressure in acute heart failure patients and the prognostic implications- report from the Tokyo cardiac care unit network emergency medical service database. Circ J 2016; 80(12): 2473-81. doi: 10.1253/circj.CJ-160837.

3. Ekundayo OJ, Saver JL, Fonarow GC, Schwamm LH, Xian Y, Zhao X, et al. Patterns of emergency medical services use and its association with timely stroke treatment: findings from Get With the Guidelines-Stroke. Circ Cardiovasc Qual Outcomes 2013; 6(3): 262-9. doi: 10.1161/circoutcomes.113.000089.

4. Ohm F, Vogel D, Sehner S, Wijnen-Meijer M, Harendza S. Details acquired from medical history and patients' experience of empathy--two sides of the same coin. BMC Med Educ 2013; 13: 67. doi: 10.1186/1472-6920-13-67.

5. Ghosh D, Karunaratne P. The importance of good history taking: a case report. J Med Case Rep 2015; 9: 97. doi: 10.1186/s13256-015-0559-y.

6. Keifenheim KE, Teufel M, Ip J, Speiser N, Leehr EJ, Zipfel S, et al. Teaching history taking to medical students: a systematic review. BMC Med Educ 2015; 15: 159. doi: 10.1186/s12909-015-0443-x.

7. Arora S, Goldberg AD, Menchine M. Patient impression and satisfaction of a self-administered, automated medical history-taking device in the emergency department. West J Emerg Med 2014; 15(1): 35-40. doi: 10.5811/ westjem.2013.2.11498.

8. Mould-Millman NK, Rominski SD, Bogus J, Ginde AA, Zakariah AN, Boatemaah CA, et al. Barriers to accessing emergency medical services in Accra, Ghana: development of a survey instrument and initial application in Ghana. Glob Health Sci Pract 2015; 3(4): 577-90. doi: 10.9745/ghsp-d-15-00170.

9. Birks M, Cant R, James A, Chung C, Davis J. The use of physical assessment skills by registered nurses in Australia: issues for nursing education. Collegian 2013; 20(1): 27-33. doi: 10.1016/j.colegn.2012.02.004.

10. Abelsson A, Lindwall L. The prehospital assessment of severe trauma patients' performed by the specialist ambulance nurse in Sweden - a phenomenographic study. Scand J Trauma Resusc Emerg Med 2012; 20: 67. doi: 10.1186/1757-7241-20-67.

11. Lammers R, Byrwa M, Fales W. Root causes of errors in a simulated prehospital pediatric emergency. Acad Emerg Med 2012; 19(1): 37-47. doi: 10.1111/j.15532712.2011.01252.x.

12. Will JC, Yuan K, Ford E. National trends in the prevalence and medical history of angina: 1988 to 2012. Circ Cardiovasc Qual Outcomes 2014; 7(3): 407-13. doi: 10.1161/circoutcomes.113.000779.

13. Oostendorp RA, Elvers H, Mikolajewska E, Laekeman M, van Trijffel E, Samwel H, et al. Manual physical therapists' use of biopsychosocial history taking in the management of patients with back or neck pain in clinical practice. ScientificWorldJournal 2015; 2015: 170463. doi: 10.1155/2015/170463.

14. Norman C, Mello M, Choi B. Identifying frequent users of an urban emergency medical service using descriptive statistics and regression analyses. West J Emerg Med 2016; 17(1): 39-45. doi: 10.5811/westjem.2015.10.28508.

15. Bhat SR, Johnson DA, Pierog JE, Zaia BE, Williams SR, Gharahbaghian L. Prehospital evaluation of effusion, pneumothorax, and standstill (PEEPS): pointof-care ultrasound in emergency medical services. West J Emerg Med 2015; 16(4): 503-9. doi: 10.5811/ westjem.2015.5.25414.

16. Pan CL, Chiu CW, Wen JC. Adaptation and promotion 
of emergency medical service transportation for climate change. Medicine (Baltimore) 2014; 93(27): e186. doi: 10.1097/md.0000000000000186.

17. Karsenty C, Landau M, Ferguson R. Assessment of medical resident's attention to the health literacy level of newly admitted patients. J Community Hosp Intern Med Perspect 2013; 3(3-4):23071. doi: 10.3402/jchimp.v3i34.23071.

18. Venkat A, Asher SL, Wolf L, Geiderman JM, Marco CA, McGreevy J, et al. Ethical issues in the response to Ebola virus disease in United States emergency departments: a position paper of the American College of Emergency Physicians, the Emergency Nurses Association, and the Society for Academic Emergency Medicine. Acad Emerg
Med 2015; 22(5): 605-15. doi: 10.1111/acem.12642.

19. Carron PN, Dami F, Diawara F, Hurst S, Hugli O. Palliative care and prehospital emergency medicine: analysis of a case series. Medicine (Baltimore) 2014; 93(25): e128. doi: $10.1097 / \mathrm{md} .0000000000000128$.

20. Sandvik H, Hunskar S, Diaz E. Which GPs are staffing the emergency medical services? Tidsskr Nor Laegeforen 2012; 132(20): 2277-80. doi: 10.4045/tidsskr.12.0198.

21. Matsuyama T, Kitamura T, Kiyohara K, Hayashida S, Kawamura T, Iwami T, et al. Characteristics and outcomes of emergency patients with self-inflicted injuries: a report from ambulance records in Osaka City, Japan. Scand J Trauma Resusc Emerg Med 2016; 24: 68. doi: 10.1186/ s13049-016-0261-0. 